
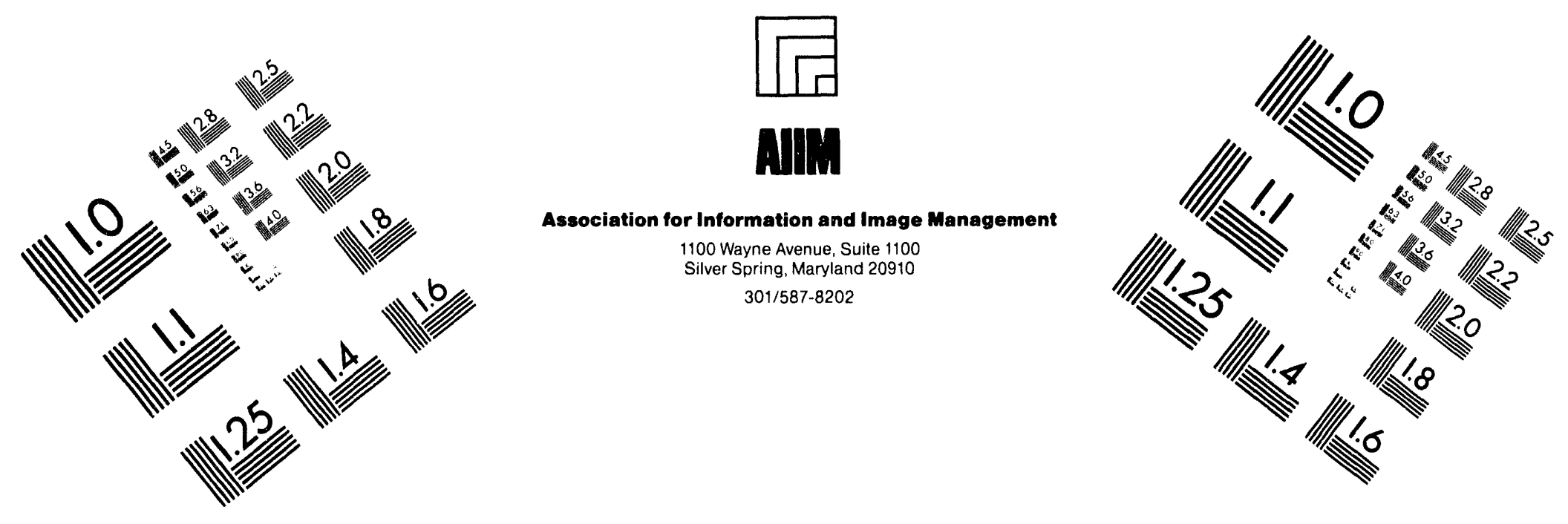

Centimeter

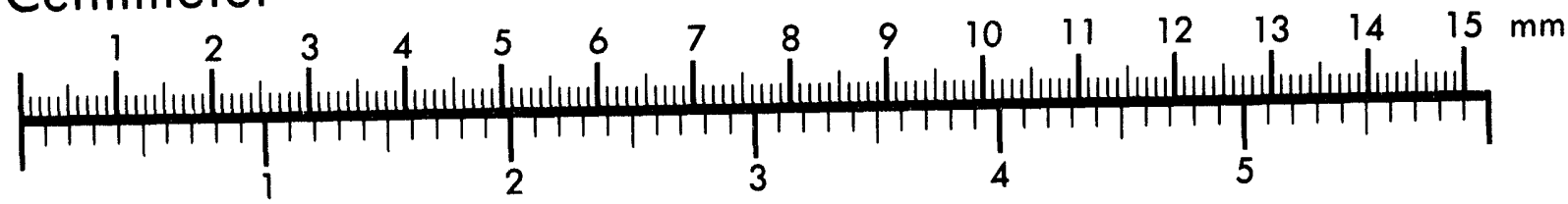
Inches
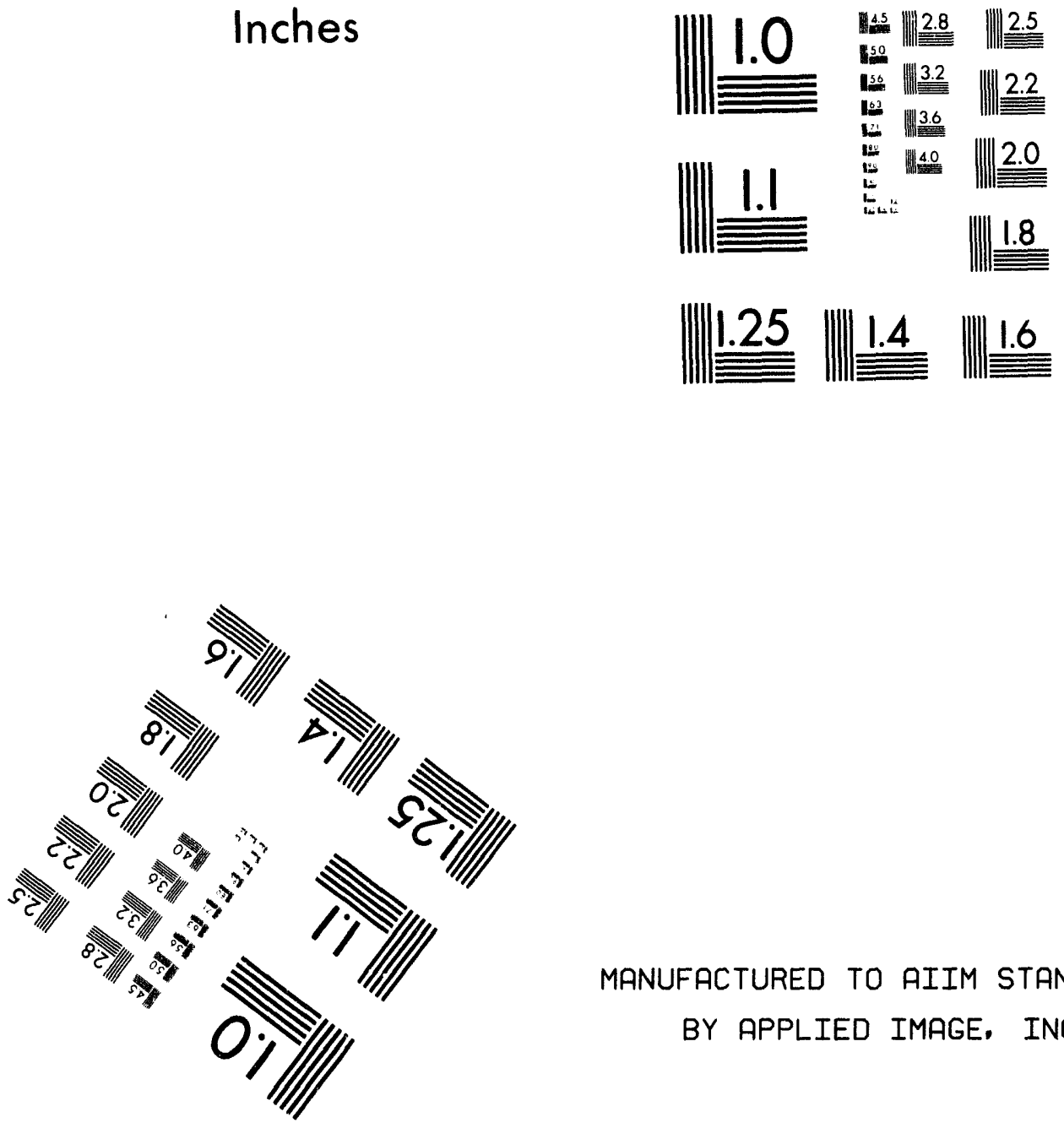

MANUFACTURED TO AIIM STANDARDS

BY APPLIED IMAGE, INC.

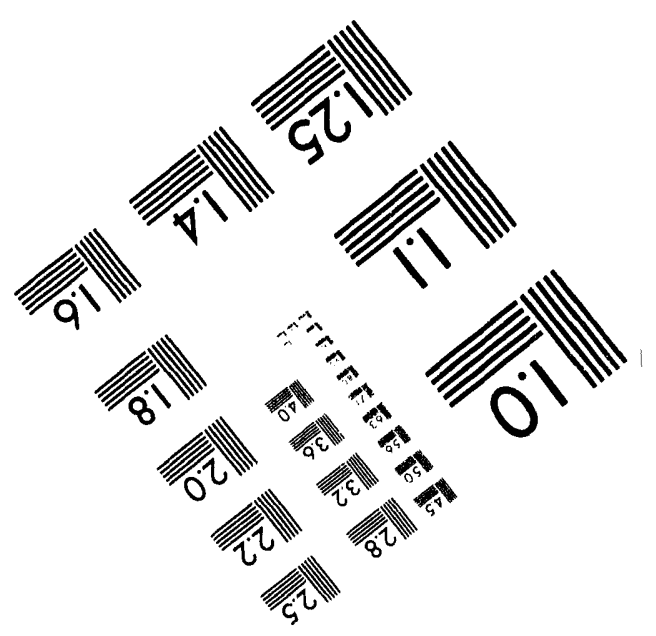



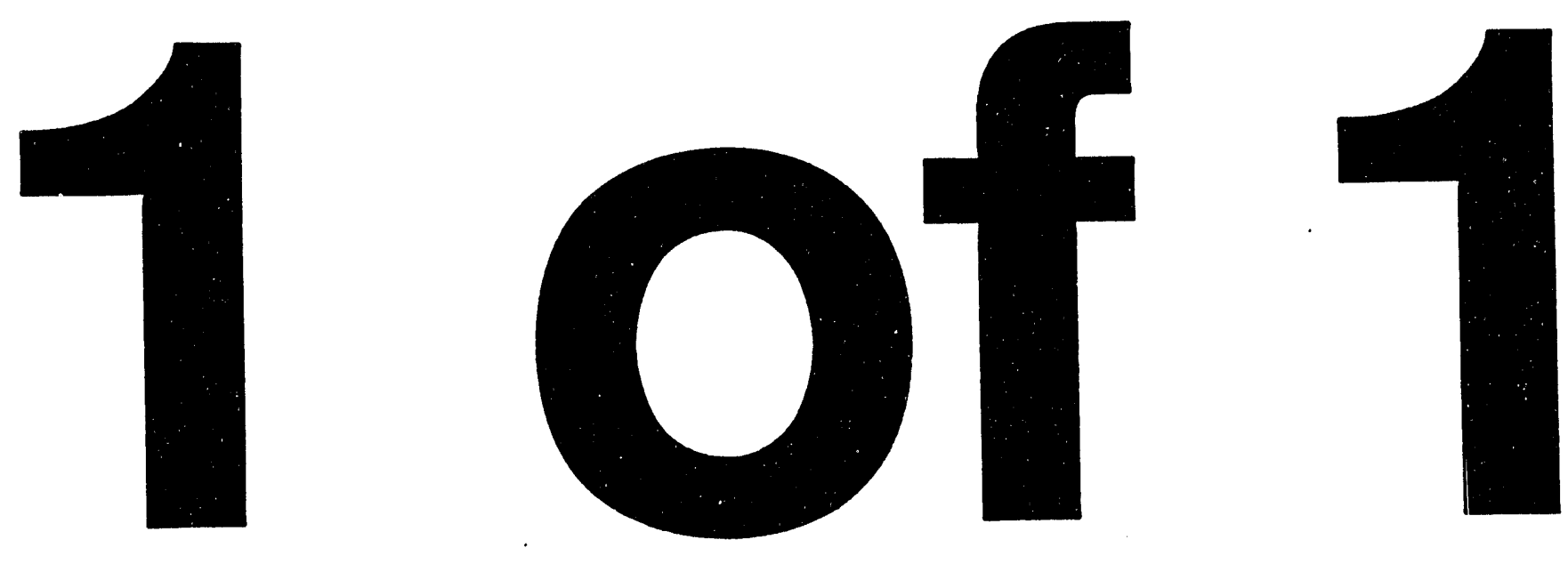


\title{
Measurements of Carbon and Tungsten Erosion/Deposition in the DIII-D Divertor
}

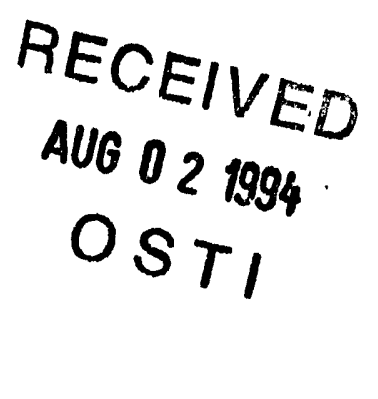

\author{
R. Bastasz, W. R. Wampler, J. W. Cuthbertson, and D. A. Buchenauer \\ Sandia National Laboratories \\ Livermore, California, USA \\ Albuquerque, New Mexico, USA
}

N. Brooks, R. Junge, W. P. West, and C. P. C. Wong

General Atomics

San Diego, California, USA

\begin{abstract}
Net erosion/deposition rates of carbon and tungsten were measured at the outer strike point of the divertor plasma on the floor of the DIII-D tokamak during deuterium $\mathrm{H}$-inode operation at a peak power deposition of about $40 \mathrm{~W} / \mathrm{cm}^{2}$. For carbon, net erosion rates of up to $4 \mathrm{~nm} / \mathrm{s}$ were found. For a tungsten film, no appreciable crosion was detected. However, measurements of deposited tungsten on adjacent carbon surfaces indicated a net $\mathrm{W}$ erosion rate of $0.06 \mathrm{~nm} / \mathrm{s}$.
\end{abstract}

\section{DISCLAIMER}

This report was prepared as an account of work sponsored by an agency of the United States Government. Neither the United States Government nor any agency thereof, nor any of their employees, makes any warranty, express or implied, or assumes any legal liability or responsibility for the accuracy, completeness, or usefulness of any information, apparatus, product, or promss disclosed, or represents that its use would not infringe privately owned rights. Reference herein to any specific commercial product, process, or service by trade name, trademark, manufacturer, or otherwise does not necessarily constitute or imply its endorsement, recommendation, or favoring by the United States Government or any agency thereof. The views and opinions of authors expressed herein do not necessarily state or reflect those of the United States Government or any agency thereof. 


\section{Introduction}

Surface erosion by energetic particles may limit the lifetime of divertor materials in fusion reactors. The net erosion rate is difficult to predict and depends on the interplay of several complex processes, including sputtering, transport, and deposition of material on divertor surfaces [1-4]. Measurements of net erosion in operating tokamaks are needed therefore to provide data under realistic conditions and to benchmark models [35] being developed to estimate erosion rates and component lifetimes in next-generation tokamaks.

We have used the Divertor Materials Evaluation System (DiMES) [6] to measure the rates of erosion and deposition of carbon and tungsten in the divertor region of the DIII-D tokamak. The DiMES mechanism enables $5 \mathrm{~cm}$ diameter samples to be remotely inserted into the DIII-D divertor and exposed under controlled conditions. After exposure, the sample is removed from DIII-D and the net amount of erosion/deposition across the sample face is measured with external instrumentation. For the carbon erosion studies, samples of type ATJ graphite were prepared with subsurface Si markers. Rutherford backscattering spectroscopy (RBS) was used to measure the change in depth of the markers and deduce the net amount of erosion/deposition on the samples. For the tungsten erosion studies, a thin layer of tungsten was deposited on a graphite sample. After exposure to the plasma, the change in thickness of the tungsten film and the amount of tungsten deposited on the surrounding carbon surfaces were measured with RBS.

\section{Apparatus and method}

The DiMES mechanism consists of a hydraulically operated shaft, which transports test samples about $1.8 \mathrm{~m}$ from a vacuum transfer chamber under the tokamak to the divertor floor of DIII-D. An inserted sample is positioned so that its front surface is coplanar to within $0.5 \mathrm{~mm}$ with the surrounding graphite divertor tiles at a radial distance of $148.5 \mathrm{~cm}$ from the centerline of the machine. When a diverted plasma's Xpoint is directly above the sample, the sample sits in the private flux region sheltered from direct plasma interaction. The X-point position can be controlled so that the outer strike point of the plasma can be moved onto the sample. Under this condition, the maximum power deposition on the sample can reach $8 \mathrm{MW} / \mathrm{m}^{2}$ with deuterium fluxes in the range of $10^{23-24} \mathrm{D} / \mathrm{m}^{2} / \mathrm{s}$ in ELMing $\mathrm{H}$-mode if all eight neutral beams are used. Samples are solid plugs of material about $5 \mathrm{~cm}$ in diameter and $7 \mathrm{~cm}$ in length. They are kept pressed against a conical lip on the divertor floor with a force of 300-650 $\mathrm{N}$ to maintain good thermal and mechanical contact.

For the carbon erosion studies, samples of graphite (type ATJ) were polished to a $0.25 \mu \mathrm{m}$ finish on their front faces, cleaned, outgassed, and then implanted with $200 \mathrm{keV}$

${ }^{29} \mathrm{Si}$ to form a reference marker $300 \mathrm{~nm}$ beneath the surface. The entire surface of the sample face was uniformly implanted to a fluence of $1 \times 10^{16} \mathrm{Si} / \mathrm{cm}^{2}$. The implanted $\mathrm{Si}$ is essentially immobile in the graphite matrix over the temperature range encountered in this study $\left(25-500^{\circ} \mathrm{C}\right)$. Several depth profiles of the implanted Si were recorded by secondary ion mass spectrometry on witness samples prepared alongside the DiMES samples to verify the depth, uniformity, and stability of the implant. 
For the tungsten erosion studies, a $1 \mathrm{~cm}$ diameter coating of tungsten, $100 \mathrm{~nm}$ in thickness, was deposited in the center of a graphite sample after it had been implanted with $\mathrm{Si}$. This preparation made it possible to make erosion/deposition measurements of both carbon and tungsten on the same sample. A diagram illustrating the features of the prepared sample is shown in Fig. 1.

In addition to routine diagnostic information about DIII-D plasma conditions, supporting diagnostics were used during the exposures to provide data about the radial heat flux profile across the sample, the electron temperature and density in the divertor, and the carbon flux at the sample. These diagnostics consisted of an IR camera, a Langmuir probe array, and a CCD camera equipped with a spectral interference filter to record carbon line emission.

The RBS analysis was conducted using a beam of $2 \mathrm{MeV} \mathrm{He}^{+}$and a Si detector to measure the energy of backscattered particles. The beam spot size was typically $1.4 \times 1.4 \mathrm{~mm}$. Spectra were recorded before and after exposure at various points on the sample, primarily along lines oriented to the DIII-D radial or toroidal directions during the sample exposure. Since the stopping power of He in carbon is well known, the change in depth of the ${ }^{29} \mathrm{Si}$ marker, and hence the net erosion or deposition of carbon, can be determined from the change in energy of He scattered from the ${ }^{29} \mathrm{Si}$ $[7,8]$.

\section{Experimental results}

\subsection{Carbon erosion}

Measurements of carbon erosion were made on three samples exposed in DIII-D, designated DiMES \# 8, 9, and 11. Following exposure in DIII-D, each sample was removed, transported in air, and RBS analysis was conducted. Representative spectra showing the scattering signal from Si before and after ex posure is shown in Fig. 2. The position of the peaks were determined by a least squares fit of a Gaussian peak on a linear background. The precision of the depth measurements is $\pm 10 \mathrm{~nm}$, based on the standard deviation of the peak centroid. Errors due to energy shifts from other causes were kept below $10 \mathrm{~nm}$ by recalibrating the energy scale for each series of measurements, using the backscattering signal from $\mathrm{C}$ and Si reference samples.

The DiMES \#8 sample was exposed to the ELM-free phases of six H-mode deuterium plasmas (shots 80136 through 80141). During these quiescent phases, which occurred twice per discharge (except on shot 80140), the strike point was positioned over the sample, giving a total exposure time of $13.5 \mathrm{sec}$ with an average thermal load of $0.45 \mathrm{MW} / \mathrm{m}^{2}$. The surface temperature rise of the sample was estimated from IR camera data to be less than $200^{\circ} \mathrm{C}$ during its exposure. The wagnetic field pitch angle on the sample was $1.2^{\circ}$. Carbon erosion was measured along four lines on DiMES \#8, three in the radial direction (Fig. 3a) and one along the toroidal direction (Fig. 3b). On this sample carbon erosion could be measured only outside the central $1 \mathrm{~cm}$ diameter $\mathrm{W}$ deposit. Net erosion was largest close to the edge of the $\mathrm{W}$ spot and and decreased towards the outer edge of the sample. RBS analysis of the $\mathrm{W}$ deposit showed the amount of carbon deposited on top of the $W$ to be less than $5 \mathrm{~nm}$.

The DiMES \#9 sample was exposed to 15 consecutive ELMing H-mode deuterium 
plasmas (shots 78828 through 78842) in which the strike point was moved onto the sample for the last second of each discharge. The magnetic field pitch angle on the sample was about $0.7^{\circ}$. The net carbon erosion/redposition profiles in the radial and toroidal directions were similar to those observed on DiMES \#8 In the radial direction, net erosion between 40 and $60 \mathrm{~nm}$ was found over most of the sample. Net deposition of about $70 \mathrm{~nm}$ was found close to the outboard edge. An abrupt increase in carbon deposition at the edge may indicate shadowing of the ion flux by a small ledge between the sample and neighboring tile. In the toroidal direction (Fig. 3b), net deposition occurred near the upfield edge of the sample and net erosion of roughly $50 \mathrm{~nm}$ was found over the rest of the sample.

One sample, DiMES \#11, was recessed several $\mathrm{cm}$ below the divertor floor during its exposure and consequently saw no direct ion flux from the plasma. RBS analysis indicated that no detectable erosion or deposition of carbon occurred on this sample (Fig. 3b).

\subsection{Tungsten erosion}

The W film thickness on DiMES \#8 was measured after exposure in DIII-D and compared with measurements made on a witness sample prepared alongside the DiMES sample. Within the resolution limits of RBS $(5 \mathrm{~nm})$, no shange was detected in the W layer thickness, indicating that the net $W$ erosion was less than $5 \mathrm{~nm}$. RBS analysis of the impurities in the $\mathrm{W}$ layer showed that it contained $15 \%$ atomic each of carbon and oxygen throughout its thickness.

The amount of $\mathrm{W}$ transported by the plasma from the original metal film deposit was also measured by RBS. The results are shown in Fig. 4 . The amount was about $4 \times 10^{15} \mathrm{~W} / \mathrm{cm}^{2}$ (equivalent to 2.5 monolayers) at the edge of the metal film and decreased nearly exponentially with distance from the film with an e-folding length of $1.9 \pm 0.4 \mathrm{~mm}$. More $\mathrm{W}$ was found in the downfield direction than in the other directions, at distances greater than $5 \mathrm{~mm}$ from the edge of the spot. Assuming all sputtered W was deposited on the surrounding sample surface, the total $W$ erosion amounts to $4.8 \times 10^{15} \mathrm{~W} / \mathrm{cm}^{2}$, or about $0.8 \mathrm{~nm}$.

\section{Discussion}

Hua and Brooks have used the computer models WBC and REDEP to predict net erosion rates of carbon and tungsten on the DiMES samples [9]. Their calculations used all available information about the magnetic field configuration, plasma conditions, and divertor geometry for the plasmas to which the DiMES samples were exposed. The WBC and REDEP codes contain no free parameters, so comparison with the measured data provides a stringent test of the codes' ability to model realistic plasmasurface interactions. The net carbon erosion predicted for DiMES \#8, for which plasma parameters were reasonably well determined, has been compared with the measured erosion and is described in detail in a companion paper [9]. Considering the uncertainty in the knowledge of input parameters to the codes, the broad general agreement that is obtained is encouraging.

The computer model of Hua and Brooks indicates the energy of the impinging deuterium ions on DiMES \#8 is below the threshold for sputtering tungsten, and that 
erosion of $\mathrm{W}$ is mainly due to sputtering by carbon ions [9]. However, the observed erosion rate is smaller than predicted by their model or measured in laboratcry experiments for a pure $W$ surface [10]. A reduction in $W$ erosion could result from a surface carbon layer as thin as a few monolayers. A thin carbon layer is likely to exist to maintain a balance between the incoming and outgoing flux of carbon atoms. The carbon influx to the surface is high enough that such a steady state carbon coverage would be established very quickly. Accumulation of a thicker carbon layer on the $W$ in the present experiment is unlikely since net erosion of carbon was observed adjacent to the W film. Furthermore, although RBS analysis showed there was less than $5 \mathrm{~nm}$ of carbon deposited on the $\mathrm{W}$, the measurements do not preclude the presence of a few monolayers of carbon.

The spatial dependence of the $\mathrm{W}$ deposition on the carbon surface, in particular the e-folding length and the preferential deposition in the downfield direction, are in good agreement with the computer model. The e-folding length for deposition depends mainly on the path length for ionization of sputtered atoms. This distance is much shorter for tungsten than for carbon. One may therefore expect that the carbon flux onto the surface of the W spot is nearly uniform, whereas the W flux onto the surrounding carbon falls off very sharply. Prediction of the correct e-folding length for impurity deposition should be a sensitive test to check that the plasma boundary conditions used by the model are accurate.

\section{Conclusions}

The observed $4 \mathrm{~nm} / \mathrm{s}$ erosion rate of carbon, if extrapolated to ITER conditions, would result in over $10 \mathrm{~cm}$ of carbon erosion per year. Such erosion rates could severely reduce the lifetime of divertor armor. Plasma/surface interactions in the divertor must therefore be carefully regulated if carbon or other low-Z divertor materials are to be used in ITER.

Erosion of high $\mathrm{Z}$ materials, such as tungsten, can be much smaller. Predictions of erosion/deposition for these materials should take into consideration not only sputtering by hydrogen isotopes, which may be negligible for low plasma-edge temperatures, but also sputtering by plasma impurities, such as carbon and oxygen. These common impurities increase erosion by contributing to sputtering, but can also docrease erosion by altering the composition of the surface being eroded.

These experiments provided a benchmark for the WBC and REDEP erosion/deposition models, which gave good qualitative agreement overall and good quantitative agreement for the case of carbon erosion. The code, if provided with accurate plasma data, appears capable of predicting net erosion/deposition rates.

\section{Acknowledgments}

We would like to acknowledge the technical support provided by J. Whaley. We thank R. Musket for arranging the sample implantations. This work was supported by the US Department of Energy under contracts DE-AC04-94AL85000 (Sandia) and DE-AC03-89ER51114 (General Atomics). 


\section{References}

[1] D. E. Post and R. Behrisch, eds., "Physics of Plasma-Wall Interactions in Controlled Fusion" (Plenum, New York, 1986).

[2] G. M. McCracken et al., Fusion Technology 1988 (Elsevier, 1989) p. 151.

[3] J. N. Brooks in: "Atomic and Plasma-Material Interaction Processes in Controlled Thermonuclear Fusion," R. K. Janev and H. W. Darwin, eds. (Elsevier, Amsterdam, 1993) p. 403.

[4] D. Naujoks, R. Behrisch, J. P. Coad, and L. C. J. M. de Kock, Nucl. Fusion 33 (1993) 581.

[5] A. Sagara, N. Noda, R. Akiyama, H. Arimoto, H. Idei, H. Iguchi, O. Kaneko, T. Kohmoto, S. Kubo, N. Matsunami, K. Matsuoka, S. Morita, O. Motojima, K. Nishimura, S. Okamura, J. Rice, T. Shoji, C. Takahasi, Y. Takita, M. Ueda, H. Yamada, and I. Yamada, J. Nucl. Mater. 196-198 (1992) 271.

[6] C. P. C. Wong, R. Junge, R. D. Phelps, P. Politzer, F. Puhn, W. P. West, R. Bastasz, D. Buchenauer, W. Hsu, J. Brooks, and T. Hua, J. Nucl. Mater. 196-198 (1992) 871.

[7] J. F. Ziegler, "Helium Stopping Powers and Ranges in All Elemental Matter," Volume 4 (Pergamon, New York, 1977).

[8] J. W. Mayer and E. Rimini, eds., "Ion Beam Handbook for Material Analysis," (Academic, New York, 1977).

[9] T. Q. Hua and J. N. Brooks, these proceedings.

[10] Y. Hirooka, M. Bourham, J. N. Brooks, R. A. Causey, G. Chevalier, R. W. Conn, W. H. Eddy, J. Gilligan, M. Khandagle, and Y. Ra, J. Nucl. Mater. 196-198 (1992) 149. 


\section{Figure Captions}

Fig. 1. Diagram of a DiMES sample prepared for carbon and tungsten erosion/deposition measurements in DIII--D. The buried Si marker enables C erosion/deposition to be measured. Measuring thickness changes of the circular $\mathrm{W}$ spot provides erosion data and measuring $\mathrm{W}$ outside the spot provides deposition data.

Fig. 2. RBS spectra from DiMES \#8 sample before (open circles) and after (filled circles) exposure to the DIII-D plasma. The curves show least squares fits of a Gaussian peak with a linear background. The shift in the Si marker depth indicates the amount of erosion/deposition. These spectra were recorded near the point of maximum oberved erosion.

Fig. 3. (a) Measured carbon erosion/deposition profiles on DiMES \#8 for three scans along the radial direction. Scan B goes through the center of the sample, while scans $\mathrm{C}$ and $\mathrm{D}$ are offset by $7 \mathrm{~mm}$ on either side of the center. The position coordinate is measured along the scan lines from the midplane of the sample in the direction indicated by the arrows in the diagram. (b) Measured carbon erosion/deposition profiles on DiMES \#8 and \#9 in the toroidal direction. The open and closed symbols represent the data from duplicate data sets recorded for each scan. The lateral extent of the analysis beam and the precision of the erosion/deposition measurements were the same for all data and are indicated by the error bars on the single data point recorded for DiMES \#11, which was sheltered from the plasma ion flux.

Fig. 4. Tungsten deposited on carbon along the toroidal and radial directions surrounding the prepared $\mathrm{W}$ layer on DiMES \#8 after exposure in DIII-D. Tungsten is preferentially transported in the downfield toroidal direction. The open symbols were measured along the same lines as the corresponding filled symbols but with a smaller analysis bean spot size of $0.3 \mathrm{~mm}$. 


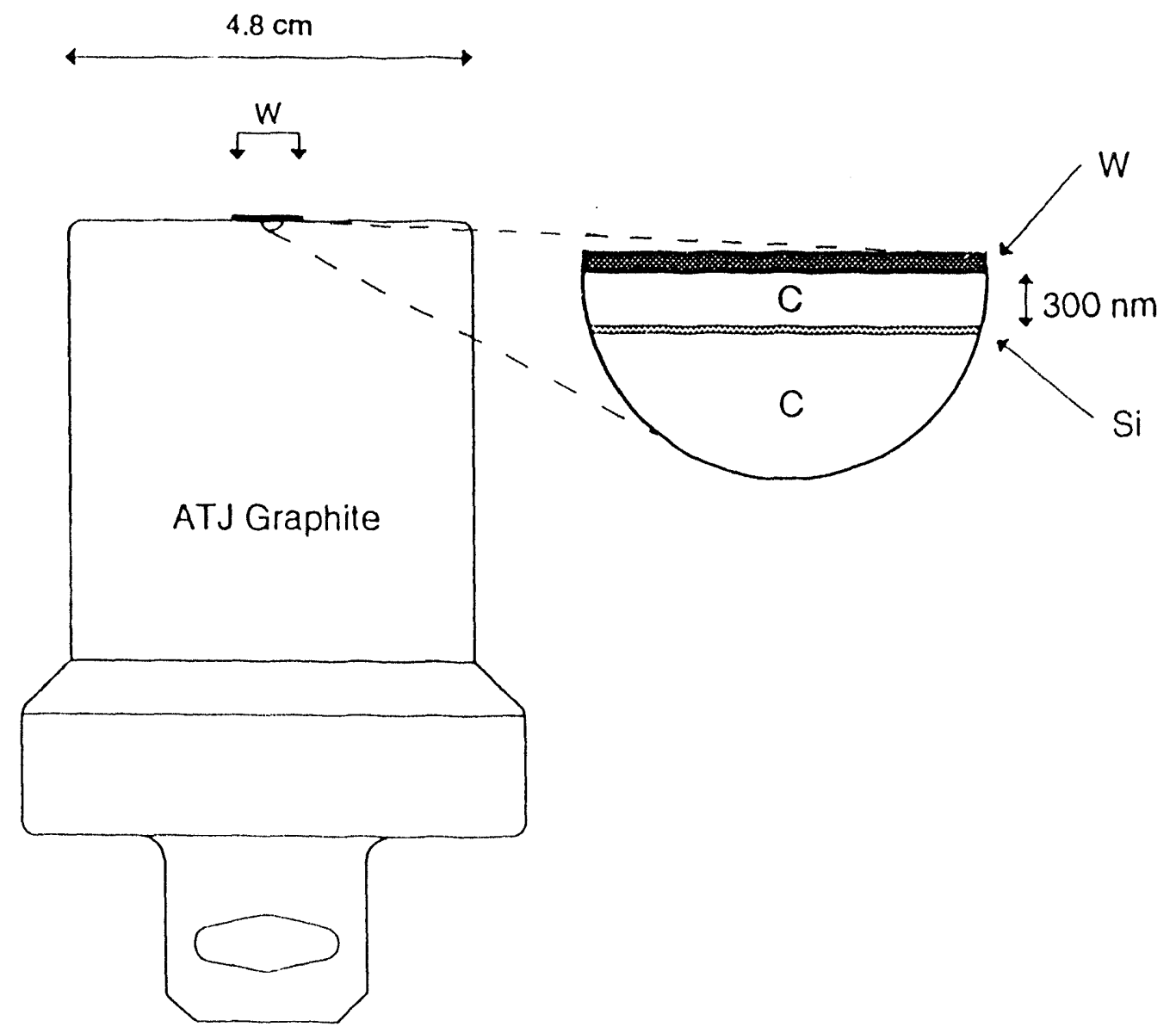

Figuale 1. 


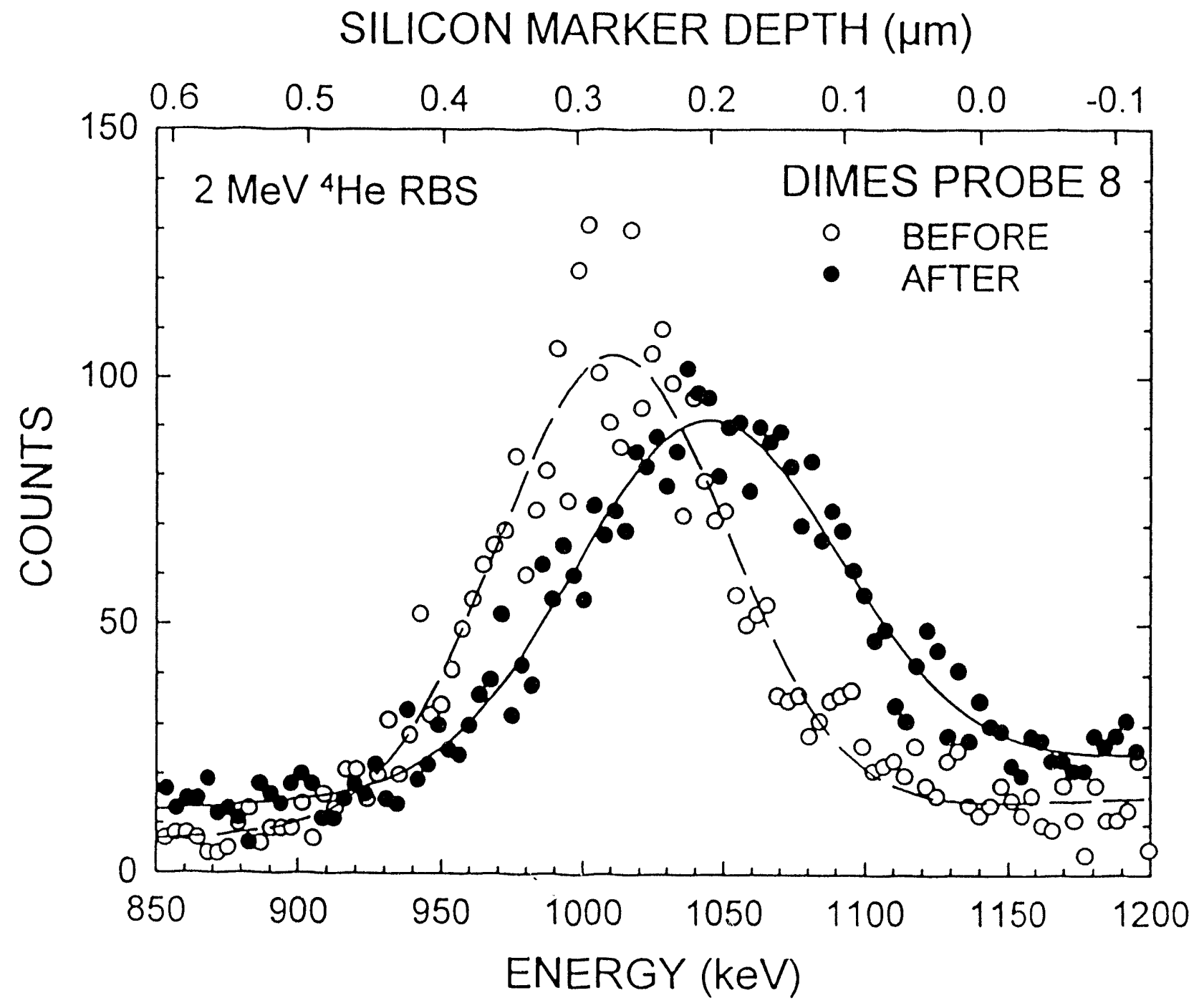

Figure 2. 


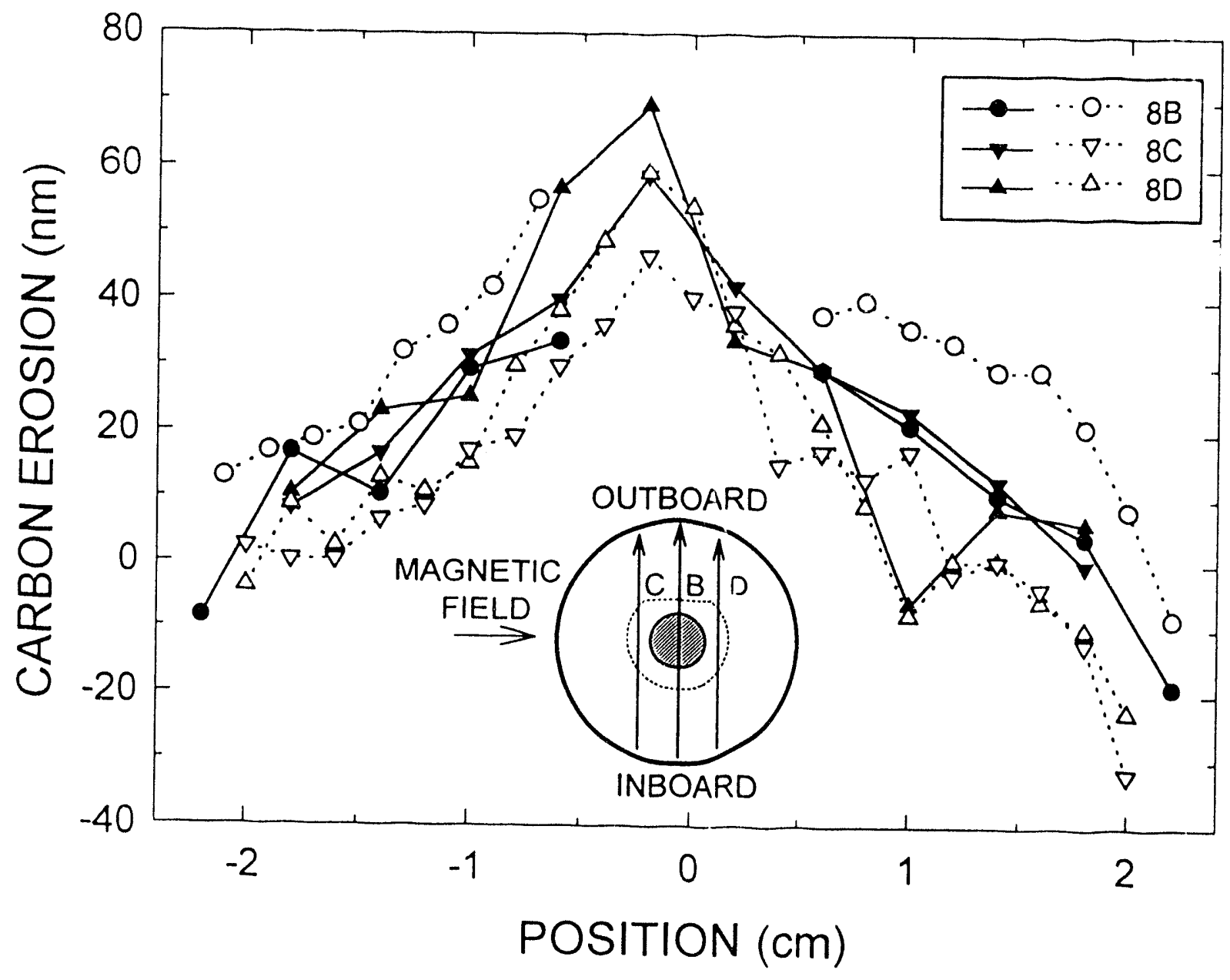

Figure $3 a$. 


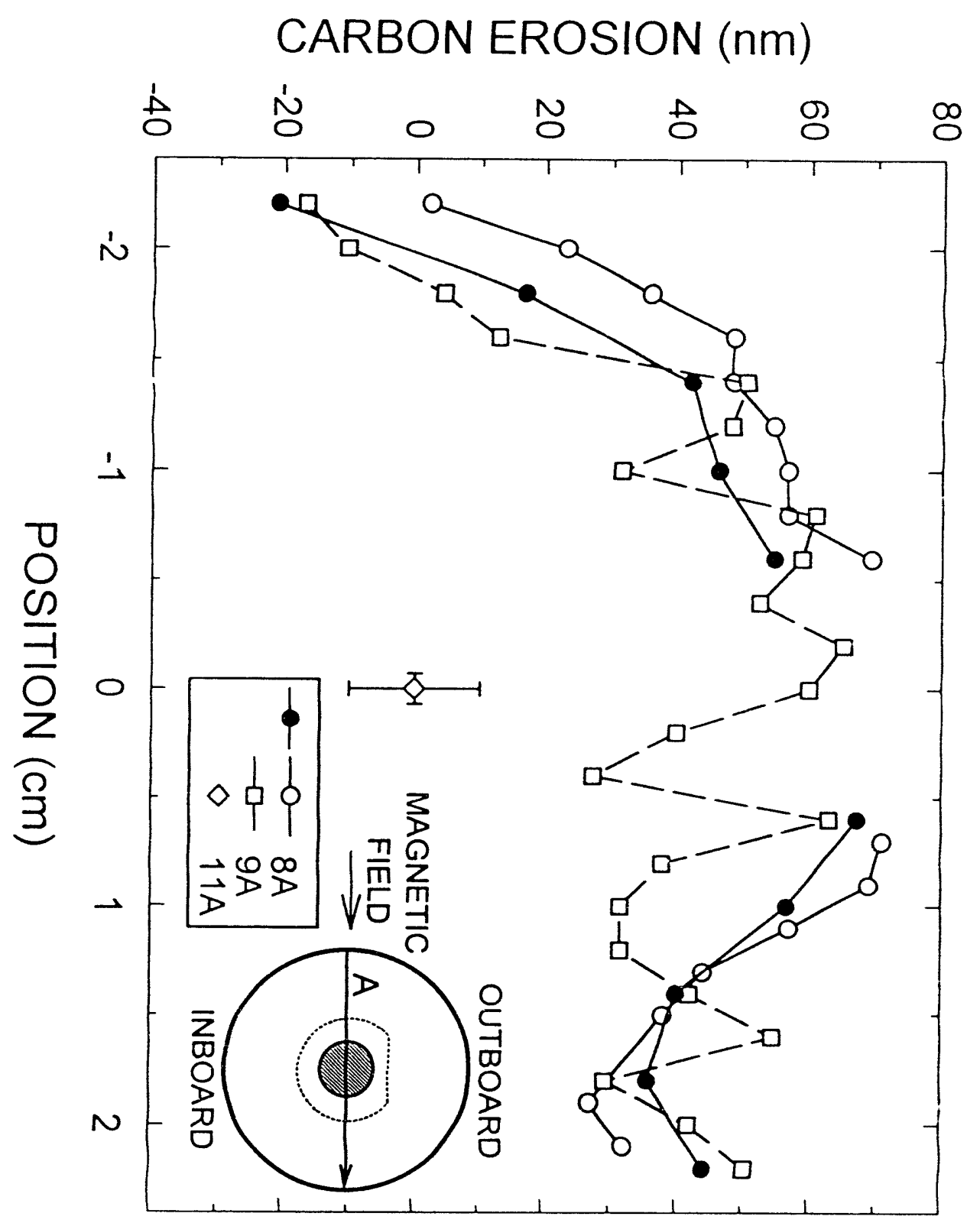




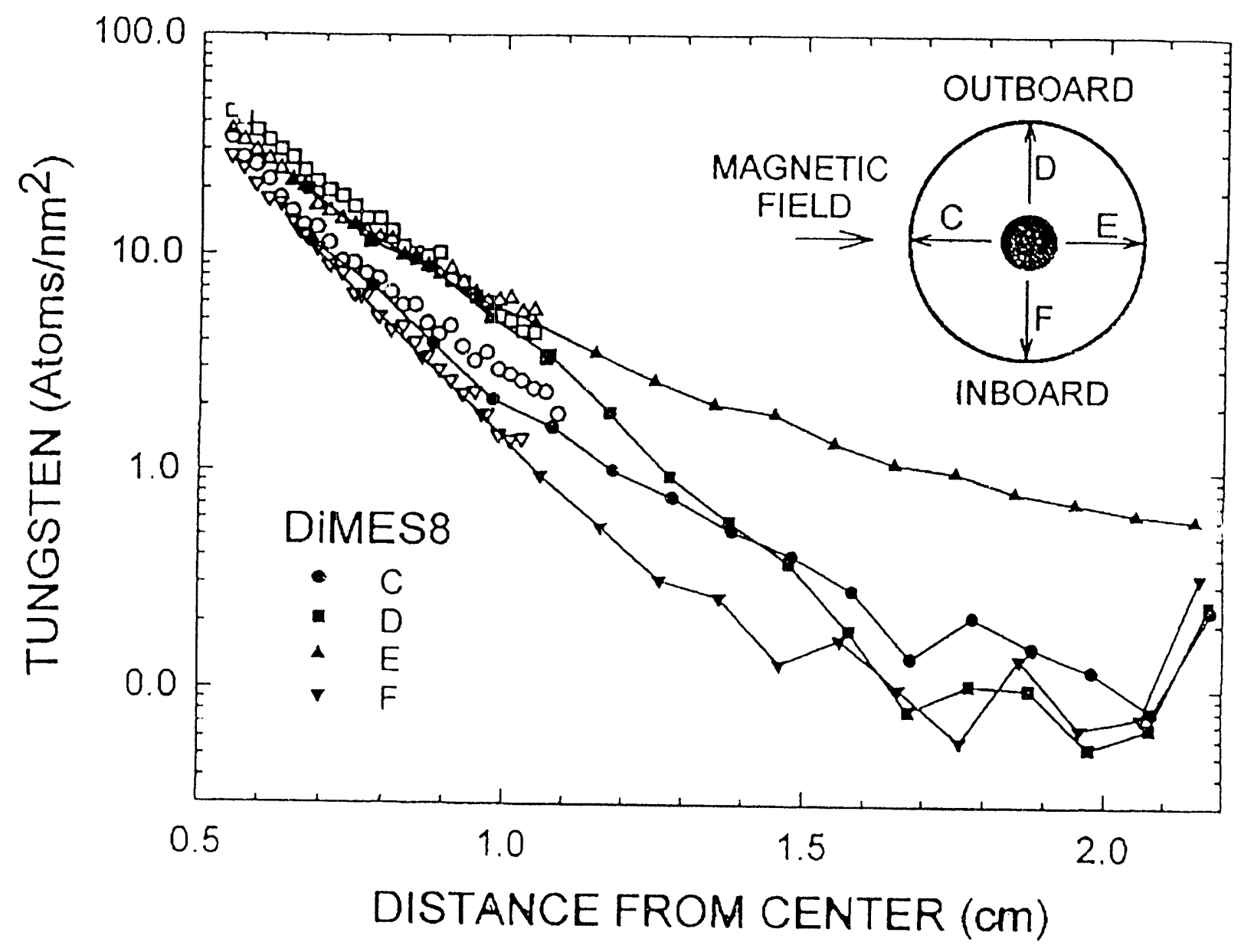

Figure 4. 

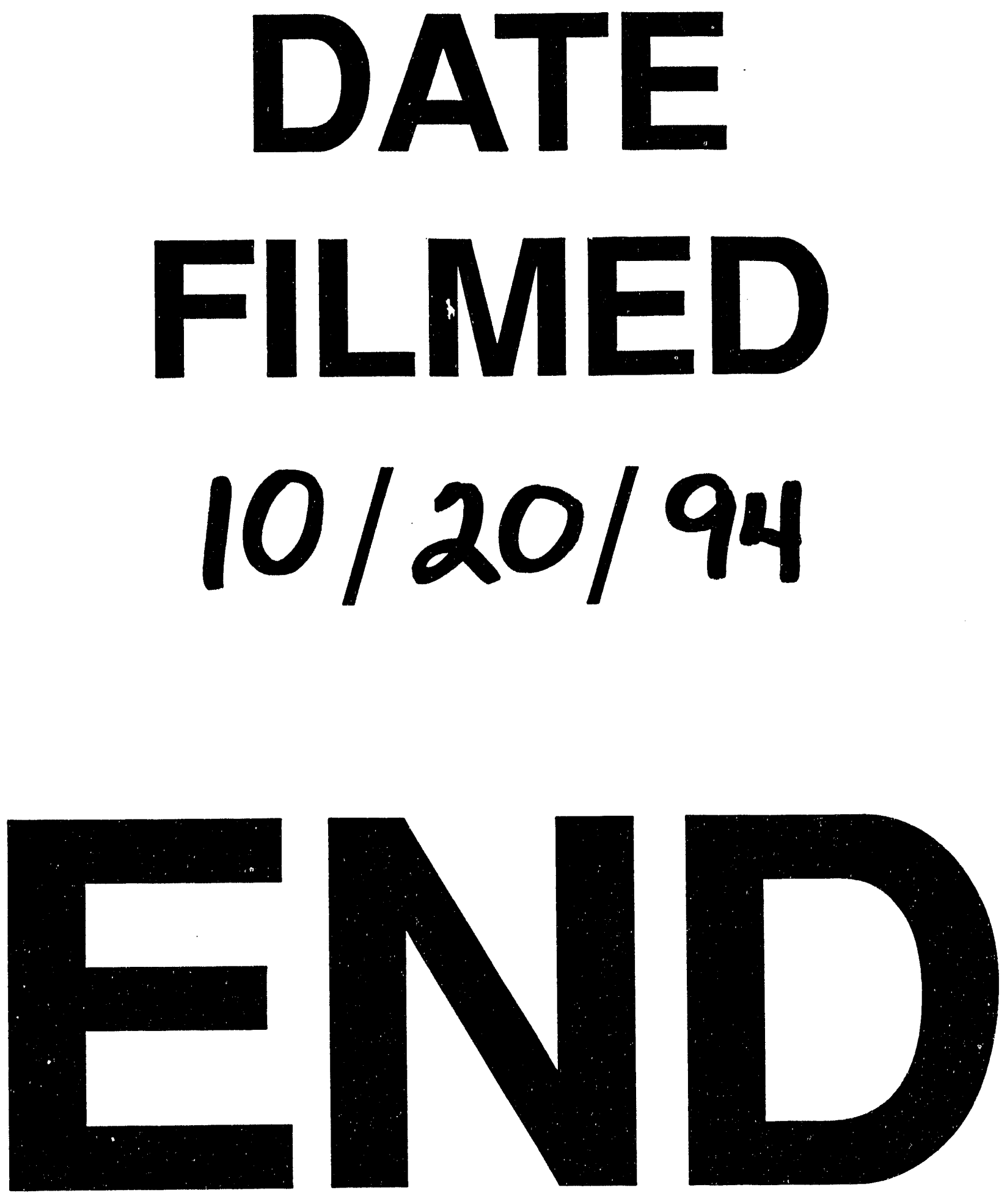
